\title{
Redox homeostasis and nitro-oxidative stress in obesity-linked inflammation.
}

\section{Authors:}

Serge P. Bottari ${ }^{1}, 2$, Margaux Di Tommaso², Hanen Samouda ${ }^{3}$.

\section{Affiliations:}

1. Medical School, Grenoble - Alps University and Endocrine and Nutritional Biochemistry, Grenoble - Alps University Hospital, Grenoble, France

2. T-RAIG, TIMC, CNRS UMR 5525, Grenoble, France

3. Department of Precision Health, Luxembourg Institute of Health, Strassen, Luxembourg.

\section{Abstract}

It is now well accepted that most chronic diseases have a common feature which is "low-grade" inflammation. Whether inflammation is causal or rather consequent to these diseases is still a matter of debate. A key factor of inflammation is considered to be "oxidative stress", which is the result of an alteration of redox homeostasis which is critical for the regulation of physiological cell and organ metabolism and proliferation. The term "oxidative stress" is however often used in an inappropriate manner as the primary target of the initial oxidative radical, superoxide ion, is nitric oxide which, being in large excess, acts as a "buffer", yielding reactive nitrogen species. It is only once the superoxide fluxes exceed the nitric oxide fluxes that true "oxidative stress" occurs. Nitro-oxidative stress is a more appropriate term which takes into account the evolving generation of reactive nitrogen and oxygen species and their effects on cell and organ pathophysiology. The molecular bases of redox homeostasis and nitro-oxidative stress will be presented and discussed using obesity-linked inflammation as a pathophysiological example. 


\section{Redox homeostasis and nitro-oxidative stress}

\section{Introduction and major molecular players}

Severe oxidative stress is fortunately a rather extreme situation observed mainly under pathological situations and the reductive mechanisms present in the cell are most often able to prevent or revert the oxidized molecules to their native reduced state [1], with the notable exception of carbonylated proteins [2], certain lipid peroxidation products such as malondialdehyde and 4-hydroxynonenal [3] and DNA [4]. These mechanisms are referred to as "redox homeostasis or regulation" and determine the activity of a series of key enzymes involved in cell metabolism, differentiation and proliferation. A major actor of redox regulation which is often neglected is $\mathrm{NO}[5,6]$. This low reactivity free radical is the preferential target of the primary oxidative species superoxide ion, $\mathrm{O}_{2}^{--}$, which oxidizes it ten times more rapidly than any cellular macromolecule [7,8] (Fig. 1). It therefore acts as a buffer for $\mathrm{O}_{2}{ }^{-*}$, especially as under "basal" physiological conditions its concentration exceeds that of superoxide $\left(10^{-12}-10^{-11} \mathrm{M}\right)$ by at least two orders of magnitude [9]. This ratio is subject to change, depending on the activation of superoxide generating enzymes including NADPH oxidases (NOX 1-5 and DUOX 1 and 2), xanthine oxidase (XO), mitochondrial respiratory chain complexes and uncoupled endothelial NO synthase (NOS 3) and reducing systems including thioredoxins, glutaredoxins, peroxiredoxins, catalase, glutathione peroxydase (GR) and the Trx system [5,10] (Fig. 1).

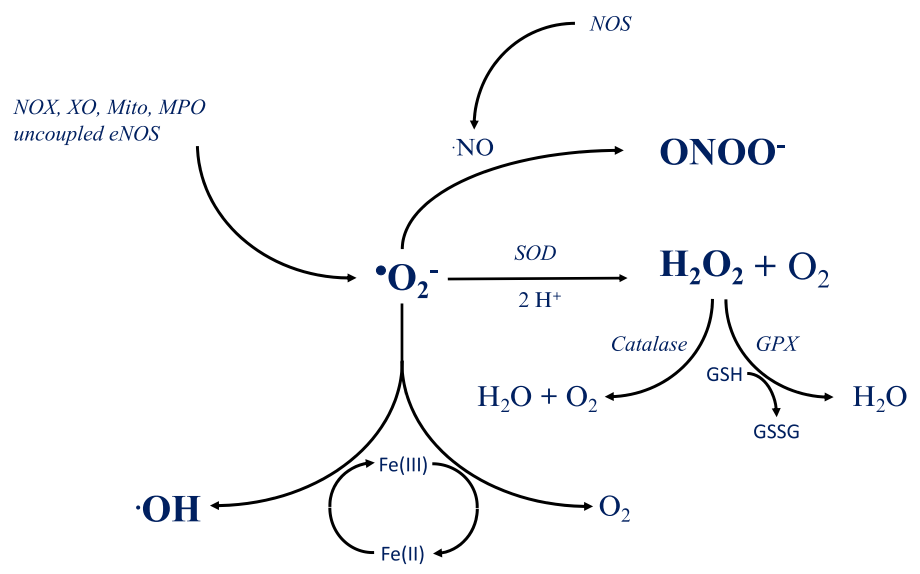

Fig. 1: Schematic representation of the major mechanisms and reactions involved in redox signaling with emphasis on the generation and degradation of reactive oxygen species (ROS) 


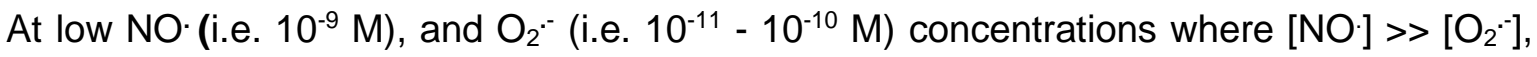
the latter will essentially regulate NO bioavailability for activating soluble guanylate cyclase (sGC) which produces cyclic GMP (cGMP), responsible for vasodilation. Activation of sGC occurs through reversible binding of NO with sub-nanomolar affinity, and is called nitrosylation. $\mathrm{O}_{2}-$ can also regulate the generation of NO- by endothelial NOS (eNOS) by uncoupling it from tetrahydrobiopterin $\left(\mathrm{BH}_{4}\right)$. The major oxidation product of $\mathrm{NO} \cdot$ when $\mathrm{O}_{2} \cdot-$ production increases to yield an [NO] / [ $\left.\mathrm{O}_{2-}^{-}\right]=2-3[11]$, is the nitrosonium ion $\mathrm{NO}^{+}$. This unstable ion can $\mathrm{S}$ nitrosate specific Cys residues (R-Cys-SH) of glutathione (GSH) and several proteins to RCys-SNO [12,13] (Fig. 2).

The exact mechanism of S-nitrosation is unknown, but may involve the formation of $\mathrm{N}_{2} \mathrm{O}_{3}$ as the concentration of $\mathrm{NO}^{+}$under "cellular" conditions is elusive due to its extremely short half-life. Another hypothesis is that S-nitroso-glutathione (GSNO) may serve as a source for protein S-nitrosation [14] (Fig. 2). This is directly involved in the cell's redox equilibrium, regulating thioredoxin activity through modification of its Cys ${ }^{69}$ residue [7]. Indeed, thioredoxin together with thioredoxin reductase and glutaredoxin together with glutathione are major reductive systems of the cell, depending on NADPH. Conversely, thioredoxin is inactivated by oxidation of its Cys $^{32}$ and Cys $^{35}$ residues, leading to apoptosis [7]. This emphasizes the importance of the $\mathrm{NO} \cdot / \mathrm{O}_{2}^{--}$ratio at low fluxes of these species for maintaining cell metabolism and life. The half-life of superoxide in aqueous solution at $\mathrm{pH} 7$ is around 5" [15], but much shorter in the cell due to the presence of SOD, and that of NO ranges between 0.01 " and 2" in cells and around $2 \times 10^{-3 "}$ in blood [5]. Considering the slow diffusion rate in cytoplasm, it is clear that in order to react, both radicals need to be produced at the same subcellular location.

Thus, S-nitrosation is a very unstable posttranslational modification which is readily reduced under physiological conditions. However, it may regulate the activity of a variety of enzymes, e.g. caspases, glyceraldehyde 3-phosphate dehydrogenase (GAPDH), aldose reductase and

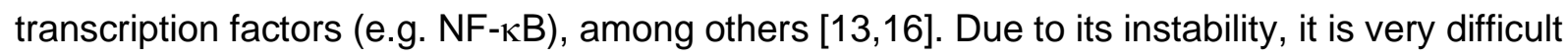
to assess S-nitrosation as the cell's redox status is almost impossible to maintain during sample extraction procedures [17]. 


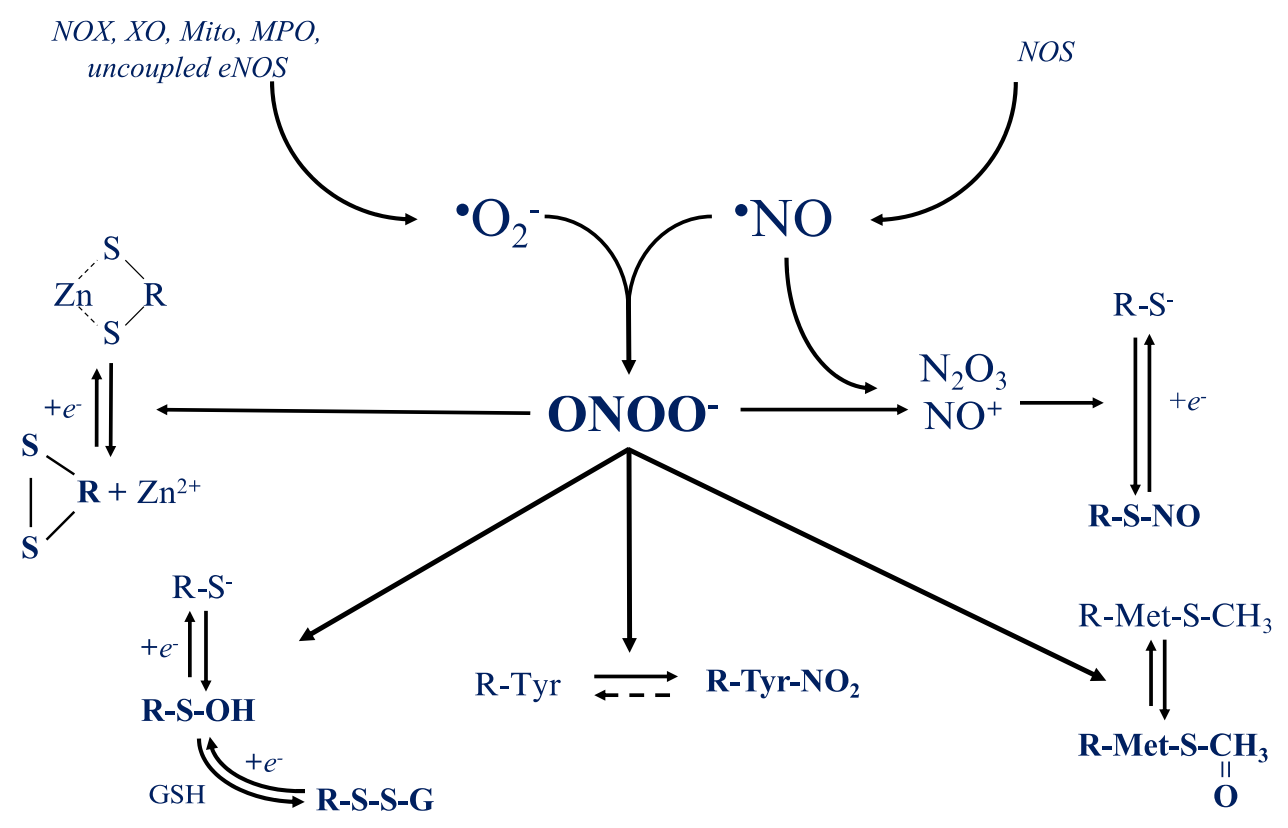

Fig. 2: Schematic representation of the major mechanisms and reactions involved in redox signaling with emphasis on the generation and effects of reactive nitrogen species (RNS)

\section{Peroxynitrite and macromolecular targets}

When $\mathrm{O}_{2}-$ fluxes increase further and its levels become equimolar with or higher than those of $\mathrm{NO}$; the two radicals react to form peroxynitrite (ONOO-) [5] (Fig. 2). This ion has a half-life of less than 1" in the cell and in the extracellular milieu, and its biological effects are thought to occur at concentrations between $10 \mathrm{nM}$ and $5 \mu \mathrm{M}$ [13]. However, whereas ONOO- concentrations may reach micromolar concentrations during inflammatory events, the levels at which it exerts its physiological effects is probably rather in the low nanomolar range [18] . The local subcellular or extracellular concentrations of peroxynitrite entirely depend on the expression level and localization of the superoxide- and NO generating enzymes. Its biological effects are concentration dependent. At concentrations $<500 \mathrm{nM}$, peroxynitrite specifically nitrates defined tyrosine (Tyr) residues of selected proteins (Fig. 2). Although peroxynitrite has also been reported to nitrate tryptophane (Trp) residues, this seems to be a rare event and its physiological relevance, especially in eukaryotes, is questionable [19]. 
The list of Tyr-nitrated proteins has been steadily growing over the past 10 years reaching close to 100 [20], which remains however far below that of phosphorylated proteins. Nitroproteins have been reported in virtually all cellular compartments and in the extracellular milieu [21]. Of note, whereas nitration was initially thought to be an irreversible posttranslational modification, it has now been reported to be reversible, with kinetics corresponding to those of enzymatic reversion of other protein modifications such as e.g. phosphorylation [22-24].

At higher concentrations (low micromolar), $\mathrm{ONOO}^{-}$will also oxidize methionine (Met) residues, resulting in their sulfoxidation [25] and sulfenylate certain cysteine thiols (Cys-SH) $[8,26]$. These can react with GSH to cause protein glutathiolation as e.g. for eNOS [27]. In zinc fingers, which allow binding of transcription factors to DNA, oxidation of adjacent Cys residues causes the formation of disulfide bridges, releasing Zn-atoms and disrupting their structure, blocking transcription. Peroxynitrite can also oxidize and inactivate protease inhibitors as well as $\mathrm{Ca}^{++}$ pumps, causing major cell dysfunction. It will also peroxidize lipids, break DNA strands and nitrate mitochondrial respiratory chain complexes, which are unaffected at lower concentrations [5,8,13] (Fig. 2). Even under these conditions, nitration of mitochondrial proteins appears to be reversible [28]. However, such effects can be very deleterious to the cell, leading to apoptosis.

\section{nNOS, eNOS, iNOS and cellular location}

In addition to the proximity and simultaneous activation of $\mathrm{NO}$ and $\mathrm{O}_{2} \cdot-$ generating systems, substrate availability also is an important factor. Whereas $\mathrm{O}_{2}$, being the substrate for $\mathrm{O}_{2} \cdot-$ production is generally available at sufficient concentrations (except in mitochondria during metabolic or respiratory stress), this is not always the case for arginine, the only substrate of NOS to generate NO: An example of this is what occurs during macrophage activation. When iNOS (NOS2) is expressed at very high levels and turned on, the arginine pool is rapidly depleted. Under such circumstances, iNOS will change its catalytic activity to oxidation, generating $\mathrm{O}_{2}{ }^{--}$ instead of NO . In addition to arginine, NOS also requires $\mathrm{NADPH}, \mathrm{FAD}, \mathrm{Zn}^{++}$and molecular oxygen. 
The third parameter is the presence and activity of the reductive systems: mainly the Trx system which includes thioredoxin, thioredoxin reductase and NADPH, the Grx system which comprises glutaredoxin, glutathione reductase, reduced glutathione (GSH) and NADPH, as well as the superoxide dismutases SOD-and 2 together with catalase and glutathione peroxidase (GPX). As indicated, these reductive systems also need common cofactors, essentially NADPH and GSH resulting in a cross-talk between them². Finally, the subcellular location of the generation systems also plays a crucial role. The NOXs are transmembrane proteins located essentially in caveolae, XO is cytosolic and respiratory chain complexes are mitochondrial. Even more complex, NOSs show translocation depending on (patho)physiological situations and their S-nitrosation or oxidation state. It is thus impossible to draw general conclusions regarding the effects of $\mathrm{ONOO}^{-}$on cell functions and biological responses without taking these factors into account.

The three NOS isoforms nNOS (neuronal NOS, NOS1), iNOS (NOS2) and eNOS (NOS3) are active under a homodimeric form and use $\mathrm{L}$-arginine as a substrate and $\mathrm{O}_{2}$ and NADPH as co-substrates. They all use FAD, FMN and $\mathrm{BH}_{4}$ as cofactors. When activated, they produce $\mathrm{NO}$, citrulline and limited amounts of $\mathrm{O}_{2} \cdot$. All three are activated by calmodulin, but whereas binding of this molecule to nNOS and eNOS requires increased cytosolic $\mathrm{Ca}^{++}$concentrations (via intracellular mobilization), it is tightly bound to iNOS even at low $\mathrm{Ca}^{++}$concentrations [29]. Thus, as opposed to eNOS/nNOS, which are activated by various extracellular mediators, iNOS is constitutively active and its effects seem to be regulated primarily through its expression levels [29].

nNOS essentially generates NO in the CNS, acting as a "long-term" mediating neurotransmitter. It is also secreted by nitrergic nerves, which innervate smooth muscle, eliciting the generation of cGMP. This mechanism seems essential for regulating vascular tone and thus blood pressure. It is also expressed in the myocardium, where it is mainly localized in the sarcoplasmic reticulum (SR), regulating ryanodine receptor $2 \mathrm{Ca}^{++}$release channel and phospholamban phosphorylation, important for Ca-influx into the SR. In skeletal muscle, nNOS plays a major role in muscle mass regulation. A splice-variant, $\mathrm{nNOS} \alpha$ has been reported to translocate to 
the nucleus, inducing mitochondriogenesis through NO mediated activation of the PGC1 pathway [30]. Another variant, nNOS $\beta$ colocalizes with soluble guanylate cyclase (sGC) in the cis-golgi to produce cGMP [31]. A third variant, $\mathrm{nNOS} \mu$ is localized in the dystrophin glycoprotein complex (DGC), involved in vasodilation and activation of the Akt/PKB pathway through ONOO-[32]. In addition, nNOS can be regulated by mitochondrial ROS [33] and by S-nitrosation in skeletal muscle [34]. These are examples of how the subcellular localization of NOS can determine firstly the generation of NO, secondly the targets and effects of NO- and thirdly, its potential oxidation to nitrosonium and peroxynitrite.

The regulation of eNOS is comparable to that of nNOS in that its activation requires $\mathrm{Ca}^{++}$ concentrations of at least $100 \mathrm{nM}$ for calmodulin binding. There are other mechanisms which can modulate its activity, among which the phosphorylation by PKB/Akt and its subcellular translocation [9]. This translocation depends on redox regulation [35]. Superoxide ions can cause glutathiolation of eNOS, inhibiting it through "uncoupling" of the $\mathrm{BH}_{4}$ cofactor [36]. In this configuration, eNOS generates $\mathrm{O}_{2}-$ instead of NO: In addition, eNOS has been reported to be subject to S-nitrosation, which inhibits its dimerization required for its enzymatic activity [37]. Regarding its subcellular localization, under basal conditions eNOS appears to be mainly located in caveolae bound to caveolin-1, functioning as an inhibitor [38]. By contrast, caveolin-1 stimulates eNOS expression and eNOS-produced NO stimulates endocytosis [31]. Interestingly, eNOS induces S-nitrosation of caveolin-1 which depolymerizes its oligomers [39]. These regulatory mechanisms are remarkable and extremely interesting, as they have been observed in diabetic patients' skeletal muscle vessels [28]. Finally, eNOS appears to also be regulated by Tyr-nitration. When nitrated, calmodulin binds to eNOS in a $\mathrm{Ca}^{++}$-independent fashion. Subsequent activation of eNOS then depends on the nitration site of calmodulin. Whereas nitration of $\mathrm{Tyr}^{99}$ inhibits it, $\mathrm{Tyr}^{138}$ nitration results in increased NO production [40].

Whereas $n$ - and eNOS activities are essential for maintaining physiological metabolism at the cellular and at the systemic levels, iNOS is the major actor in inflammation, especially during acute inflammation [41]. This does not mean that the first two isoforms are not involved in inflammation as their activity and location are directly modulated by ROS up to the point that 
eNOS can switch to an $\mathrm{O}_{2}-$ generating enzyme when uncoupled. This uncoupling is a typical consequence of low-grade chronic inflammation, observed in hypertension, dyslipidemia, metabolic syndrome (MetS), prediabetes (PD) and type 2 diabetes (T2D), resulting in endothelial damage and vascular remodeling $[42,43]$. Similar examples exist for nNOS $[44,45]$.

iNOS, being constitutively active, differs in that its biological effects are primarily regulated by its degree of expression, which is modulated by among others by inflammatory mediators and cytokines. Once its expression is induced it can generate NO for several days at micromolar fluxes [46]. Besides its regulation at the transcriptional and translational levels, its activity is also tightly controlled both by proteolytic degradation and, as stated earlier, by arginine bioavailability [47]. iNOS is found in a variety of cell types, but its major expression site is leucocytes. In these cells, cytokines and bacterial lipopolysaccharides (LPS) mimicking infection, can induce a strong expression. Other factors such as protein-protein interactions, e.g. with p53 and thrombospondin, also regulate iNOS activity [48]. An interesting role of iNOS is the dominant NO concentration gradient it induces in tissues. Whereas local NO levels adjacent to cytokine-activated macrophages are micromolar and thus cytotoxic, a few cell layers further its concentration is much lower, exerting anti-apoptotic and proliferative effects, protecting tissue and stimulate healing following damage by invading pathogens [48].

In summary, generation of micromolar fluxes of $\mathrm{NO}$ and formation of RNS/ ROS cannot be considered as deleterious or detrimental per se. Since most posttranslational modifications caused by RNS are less toxic than those due to ROS and are reversible, NO can be considered as a buffer for $\mathrm{O}_{2}-$ and thus as a complement to the reductive systems, allowing restoration of the redox equilibrium and normal cellular homeostasis. Cytotoxic effects will only occur when RNS concentrations exceed the cells' reducing capacity, causing lipid peroxidation and DNA strand breaks, leading to apoptosis. This happens when the $\mathrm{O}_{2} \cdot-$ concentration exceeds that of $\mathrm{NO}$, producing highly reactive oxidants $\left(\mathrm{OH} \cdot\right.$ and $\mathrm{NO}_{2} \cdot$ radicals) which can cause irreversible protein carbonylation and DNA strand breaks [5,8,13] (Fig. 2). 


\section{Obesity and inflammation}

Oxidative stress is a major risk factor for non-communicable diseases, including cardiometabolic, neurodegenerative, osteoarticular, kidney and oncologic pathologies, which are leading causes of disability and early death [49-53]. High oxidative stress levels have been associated with low-grade chronic inflammation. More precisely, both oxidative stress and inflammation have been shown to exacerbate one another [54]. Low-grade chronic inflammation is a common pathologic state in obesity, in particular associated with metabolically unhealthy overweight and obesity $[55,56]$. Metabolically unhealthy overweight (MUOV) and metabolically unhealthy obesity (MUO) have been defined as the two sub-phenotypes of overweight and obesity associated with at least one cardiometabolic abnormality amongst inflammation, oxidative stress, hyperglycaemia, insulin resistance, dyslipidaemia and/or hypertension, as well as an increased risk of developing cardiometabolic comorbidities [56-59]. Conversely, metabolically healthy obesity $(\mathrm{MHO})$ and metabolically healthy overweight (MHOV), emerged as the new concept of the healthy overweight and obesity sub-phenotypes, characterised by high values of body mass index $\left(\mathrm{BMI} \geq 25 \mathrm{~kg} / \mathrm{m}^{2}\right.$ ), yet an absence of the aforementioned cardiometabolic issues $[58,60,61]$. MHOV accounts for about $50 \%$ of the overweight phenotypes and $\mathrm{MHO}$ accounts for about $30 \%$ of the obesity phenotypes [58].

MHO might convert into MUO in some individuals, in particular in the absence of high levels of cardiorespiratory fitness $[58,62]$. The transition from a $\mathrm{MHO}$ to a MUO profile also occurs in the presence of a chronic state of subclinical inflammation including high levels of C-reactive protein (CRP) serum concentrations in addition to different other mediators of inflammation, in particular tumor necrosis factor (TNF- $\alpha$ ) and interleukins (IL)-6 and IL-8, as well as adipokines such as adiponectin, leptin and resistin. Low-grade chronic inflammation leads to insulin resistance [63-68] resulting in prediabetes with a potential evolution to T2D.

Furthermore, MUO is characterised by adipose tissue dysfunction due to its infiltration by immune cells including macrophages and lymphocytes, which lead to low-grade inflammation, insulin-resistance, metabolic syndrome, type 2 diabetes, hypertension and dyslipidemia [6974]. These comorbidities have in particular been associated with visceral adiposity [75]. In the 
presence of a positive energy balance, the hyperplasia and hypertrophy of the adipocytes in subcutaneous fat have been shown to be protective against cardiometabolic complications in obesity, preserving the $\mathrm{MHO}$ phenotypes. However, in the presence of a dysfunctioning subcutaneous adipose tissue characteristic of the MUO phenotypes, the subcutaneous fat displays a very limited storage capacity which leads to an ectopic accumulation of the fat, in particular in the visceral area, a chronic low-grade inflammation and the development of insulin-resistance and related cardiometabolic comorbidities [76,77].

Visceral obesity characterised by visceral adipose tissue (VAT) accumulation is a major risk factor for developing MUOV and MUO [55]. Repeatedly, VAT liberates pro-inflammatory cytokines into the portal vein, in particular TNF- $\alpha$, inducing low-grade chronic inflammation leading to the development of cardiovascular diseases associated with MUOV and MUO [78].

The adipocytes are hypertrophied in the individuals having overweight and obesity, which might partly deprive them from oxygen, inducing a lack of vascularisation and a hypoxia leading to the expression of the inflammatory genes in the expanded adipocytes [79]. The hypoxic state is particularly marked in the visceral adipocytes, compared to the subcutaneous adipocytes $[79,80]$. When prolonged, the hypoxic state has been shown to increase inflammation and insulin resistance [81,82]. In addition, the macrophage infiltration into visceral adipose tissue has been shown to be higher than in subcutaneous fat, which might be responsible for the inflammatory processes linking the ectopic accumulation of fat and the health-related issues $[79,83-85]$.

Furthermore, pro-inflammatory adipokines disorders have been highlighted in MUO as inducing the inflammatory reactions related to increased adiposity [86]. In particular, the pro-inflammatory processes observed at the visceral adipose tissue level are mainly induced by the adipokines. For example, leptin resistance resulting from the visceral adiposity increase dysregulates the leptin signalling and fuels inflammation through the increase of cytokine production in the blood $[63,87,88]$. The expression of leptin in the visceral adipose tissue has been associated with the angiotensin-converting enzyme 2 (ACE2) expression, highly concentrated in 
the visceral adipocytes and significantly associated with the comorbidities observed in the individuals having MUO, in particular hypertension [89]. Furthermore, the expression of the adiponectin gene is very low in the visceral adipose tissue, in comparison to its expression in the subcutaneous fat compartment, blunting its anti-inflammatory properties in MUO [79,90]. Currently, more than 20 adipokines which have been associated with increased adiposity, are released by the adipocytes and induce the release of a series of inflammatory cytokines, such as resistin, interleukin 1, interleukin 6 and TNF- $\alpha$ [67,91,92] (Fig. 3).

Actually, the adipose tissue contains a high number of immune cells (macrophages, mast cells, B cells, Th1 CD4 T and CD8 T cells) which increase in both number and activity, in obesity thereby leading to a pro-inflammatory status [69].

Furthermore, the white adipose tissue (WAT) located in the visceral adipose tissue (VAT) has been associated with a higher pro-inflammatory action than in subcutaneous WAT (SWAT), due to a higher macrophages availability than in the latter [93-95]. In addition, the inflammation of the VAT is associated with a low lipogenic markers expression in visceral obesity that has been associated with cardiometabolic diseases. Adipocyte hypertrophy has also been shown to be more pronounced in VAT than in subcutaneous adipose tissue (SAT), triggering the development of insulin-resistance and type 2 diabetes [93,96,97]. There are two major differences which are intimately interrelated between lean and hypertrophic VAT found in obesity, regarding its immune phenotype. First, the adipokines secreted by adipocytes in people with a lean phenotype are predominantly adiponectin, adipsin and omentin, whereas in hypertrophic VAT these adipokines decrease and conversely leptin, visfatin, resistin and chemerin are increased [98] (Fig. 3). These latter adipokines have proinflammatory properties and favour the attraction of inflammatory immune cells. Thus, whereas in low VAT depots one finds essentially eosinophils, iNKT, Tregs, Th2 cells and M2 macrophages, hypertrophic VAT is infiltrated by monocytes which differentiate into M1 macrophages, neutrophils, Th1, Th17 and B lymphocytes [98] (Fig. 3). The interleukin profile is modified accordingly. In low VAT depots, these are essentially IL-4, IL-10 and IL-13 which induce the differentiation of the macrophages to the "anti-inflammatory" M2 phenotype. In visceral obesity, the "anti-inflammatory" interleukins are 
decreased and the "pro-inflammatory" cytokines, TNF- $\square, \mathrm{IL}-1 \mathrm{~B}, \mathrm{IL}-6, \mathrm{IL}-18$ and MCP-1 are secreted, in particular by the M1 macrophages [98,99] [100,101] (Fig. 3). In addition, the now larger adipocytes have increased lipolysis and release free fatty acids which also trigger the differentiation of the resident M2 and newly attracted monocytes to the inflammatory M1 phenotype $[98,99]$. This inflammatory response also induces adipocyte necrosis thereby releasing other pro-inflammatory substances (Fig. 3).

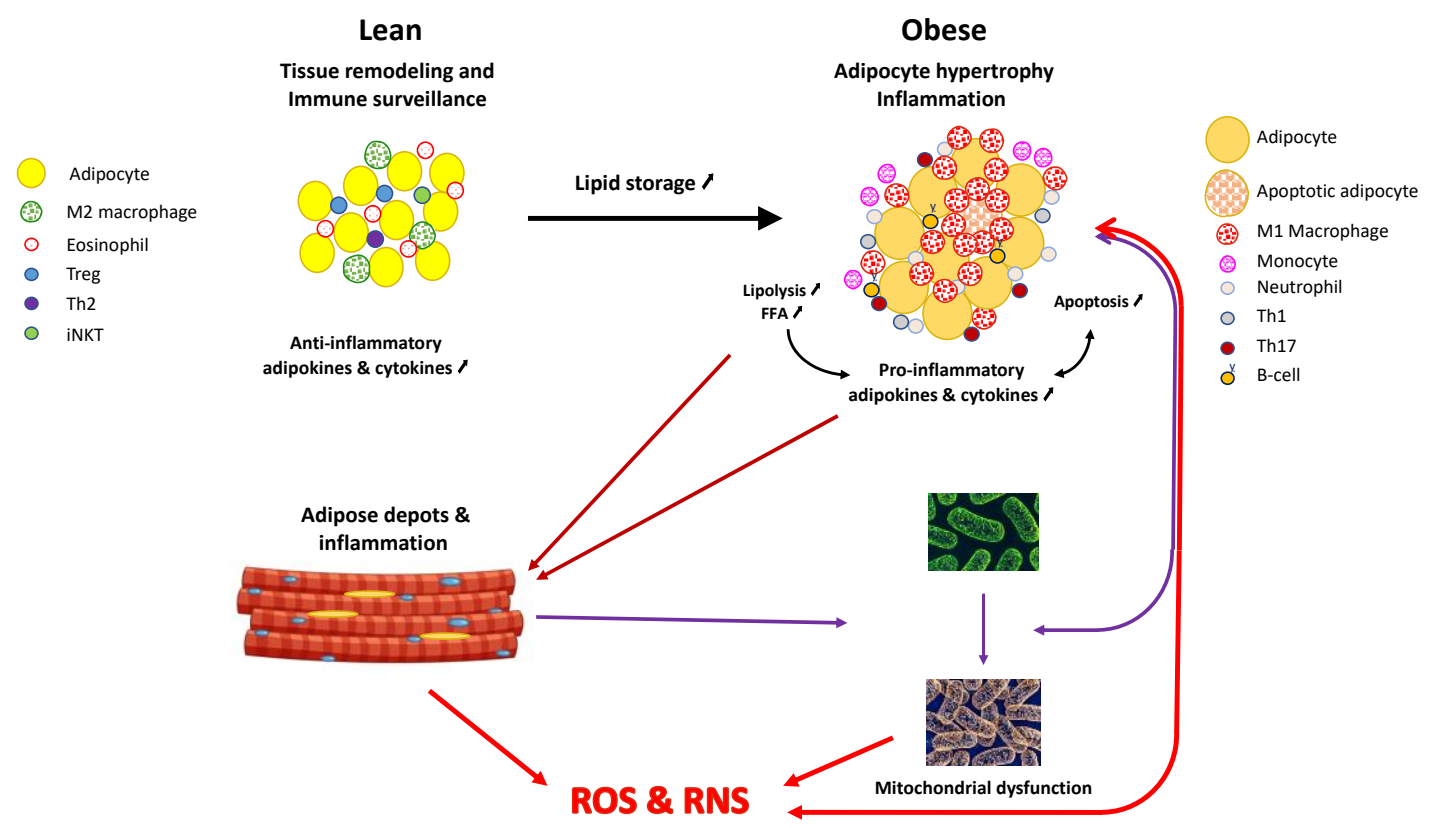

Fig. 3: Impact of obesity on the metabolism and immune status of visceral adipose tissue and its effects on reactive species generation. Consequences on skeletal muscle and mitochondrial dysfunction are highlighted.

\section{Obesity and nitro-oxidative stress}

As described above, in obesity VAT becomes a site of chronic inflammation [98,99]. In addition to the immune cells, especially the M1 macrophages which generate large amounts of ROS and hence also of RNS, the hypertrophic adipocytes also display increased ROS production due to altered mitochondrial function [102]. Not only is the biogenesis and thus the density of mitochondria decreased in these adipocytes, but so are also their metabolic functions such as fatty acid and branched-chain aminoacid (BCAA) oxidation, oxidative phosphorylation, beta 
oxidation and Krebs or tricarboxylic acid (TCA) cycle are all impaired. Slowdown of the TCA cycle which is further aggravated by reduced glucose uptake and oxidation, results in additional reduction of mitochondrial ATP synthesis and respiration. This decreased respiration due to substrate deficit is the major cause for increased ROS and RNS generation by the hypertrophic adipocytes' mitochondria (Fig. 3).

Recently a new paradigm called mitochondrial transfer has emerged. This mechanism, reported in several cells, consists in the extrusion of mitochondria which are subsequently taken up by "acceptor" cells [103]. In obesity, the hypertrophic adipocytes extrude dysfunctional mitochondria which are taken up either locally by macrophages [104], fibroblasts and progenitors or by more distant targets where they may contribute to affect cell differentiation and metabolism $[105,106]$.

Interestingly, similar observations have been made in the skeletal muscle [107-109] in obesity as well. Indeed, skeletal muscle becomes infiltrated by the adipose tissue which exhibits the same inflammatory phenotype as found in visceral obesity [110]. The same causes having the same effects, muscle also displays an inflammatory profile in this situation (Fig. 3).

Skeletal muscle accounts for the main tissue and mitochondrial mass of the body. Mitochondrial dysfunction therefore not only has major metabolic effects including insulin-resistance, but also contributes in a very significant manner to increased ROS and RNS generation. In the case of obesity, skeletal muscle together with VAT therefore becomes the major sites of nitrooxidative stress.

The question whether nitro-oxidative stress precedes or follows inflammation is still a matter of speculation and debate, but their close entanglement is a clear fact leading to a vicious circle [111] but understanding its mechanisms paves the way for novel therapeutic strategies. 


\section{References}

1. Egea, J.; Fabregat, I.; Frapart, Y.M.; Ghezzi, P.; Gorlach, A.; Kietzmann, T.; Kubaichuk, K.; Knaus, U.G.; Lopez, M.G.; Olaso-Gonzalez, G.; et al. Corrigendum to "European contribution to the study of ROS: A summary of the findings and prospects for the future from the COST action BM1203 (EU-ROS)" [Redox Biol. 13 (2017) 94-162]. Redox Biol 2018, 14, 694-696, doi:10.1016/j.redox.2017.10.001.

2. Akagawa, M. Protein carbonylation: molecular mechanisms, biological implications, and analytical approaches. Free Radic Res 2021, 55, 307-320, doi:10.1080/10715762.2020.1851027.

3. Ayala, A.; Munoz, M.F.; Arguelles, S. Lipid peroxidation: production, metabolism, and signaling mechanisms of malondialdehyde and 4-hydroxy-2-nonenal. Oxid Med Cell Longev 2014, 2014, 360438, doi:10.1155/2014/360438.

4. Dizdaroglu, M.; Coskun, E.; Jaruga, P. Measurement of oxidatively induced DNA damage and its repair, by mass spectrometric techniques. Free Radic Res 2015, 49, 525-548, doi:10.3109/10715762.2015.1014814.

5. Beckman, J.S. The double-edged role of nitric oxide in brain function and superoxide-mediated injury. J Dev Physiol 1991, 15, 53-59.

6. Cipak Gasparovic, A.; Zarkovic, N.; Zarkovic, K.; Semen, K.; Kaminskyy, D.; Yelisyeyeva, O.; Bottari, S.P. Biomarkers of oxidative and nitro-oxidative stress: conventional and novel approaches. Br J Pharmacol 2017, 174, 1771-1783, doi:10.1111/bph.13673.

7. Beckman, J.S.; Koppenol, W.H. Nitric oxide, superoxide, and peroxynitrite: the good, the bad, and ugly. Am J Physiol 1996, 271, C1424-1437, doi:10.1152/ajpcell.1996.271.5.C1424.

8. Radi, R. Peroxynitrite, a stealthy biological oxidant. J Biol Chem 2013, 288, 26464-26472, doi:10.1074/jbc.R113.472936.

9. Chance, B.; Sies, H.; Boveris, A. Hydroperoxide metabolism in mammalian organs. Physiol Rev 1979, 59, 527-605, doi:10.1152/physrev.1979.59.3.527.

10. Lu, J.; Holmgren, A. The thioredoxin antioxidant system. Free Radic Biol Med 2014, 66, 75-87, doi:10.1016/j.freeradbiomed.2013.07.036.

11. Daiber, A.; Frein, D.; Namgaladze, D.; Ullrich, V. Oxidation and nitrosation in the nitrogen monoxide/superoxide system. J Biol Chem 2002, 277, 11882-11888, doi:10.1074/jbc.M111988200.

12. Ullrich, V.; Kissner, R. Redox signaling: bioinorganic chemistry at its best. J Inorg Biochem 2006, 100, 2079-2086, doi:10.1016/j.jinorgbio.2006.09.019.

13. Frein, D.; Schildknecht, S.; Bachschmid, M.; Ullrich, V. Redox regulation: a new challenge for pharmacology. Biochem Pharmacol 2005, 70, 811-823, doi:10.1016/j.bcp.2005.04.012.

14. Broniowska, K.A.; Diers, A.R.; Hogg, N. S-nitrosoglutathione. Biochim Biophys Acta 2013, 1830, 3173-3181, doi:10.1016/j.bbagen.2013.02.004.

15. Marklund, S. Spectrophotometric study of spontaneous disproportionation of superoxide anion radical and sensitive direct assay for superoxide dismutase. J Biol Chem 1976, 251, 75047507. 
16. Hildebrandt, T.; Knuesting, J.; Berndt, C.; Morgan, B.; Scheibe, R. Cytosolic thiol switches regulating basic cellular functions: GAPDH as an information hub? Biol Chem 2015, 396, 523537, doi:10.1515/hsz-2014-0295.

17. Bechtold, E.; King, S.B. Chemical methods for the direct detection and labeling of Snitrosothiols. Antioxid Redox Signal 2012, 17, 981-991, doi:10.1089/ars.2012.4570.

18. Bachschmid, M.; Schildknecht, S.; Ullrich, V. Redox regulation of vascular prostanoid synthesis by the nitric oxide-superoxide system. Biochem Biophys Res Commun 2005, 338, 536-542, doi:10.1016/j.bbrc.2005.08.157.

19. Nuriel, T.; Hansler, A.; Gross, S.S. Protein nitrotryptophan: formation, significance and identification. J Proteomics 2011, 74, 2300-2312, doi:10.1016/j.jprot.2011.05.032.

20. Batthyány, C.; Bartesaghi, S.; Mastrogiovanni, M.; Lima, A.; Demicheli, V.; Radi, R. TyrosineNitrated Proteins: Proteomic and Bioanalytical Aspects. Antioxid Redox Signal 2017, 26, 313328, doi:10.1089/ars.2016.6787.

21. Wayenberg, J.L.; Cavedon, C.; Ghaddhab, C.; Lefevre, N.; Bottari, S.P. Early transient hypoglycemia is associated with increased albumin nitration in the preterm infant. Neonatology 2011, 100, 387-397, doi:10.1159/000326936.

22. Pinzar, E.; Wang, T.; Garrido, M.R.; Xu, W.; Levy, P.; Bottari, S.P. Angiotensin II induces tyrosine nitration and activation of ERK1/2 in vascular smooth muscle cells. FEBS Lett 2005, 579, $5100-$ 5104, doi:10.1016/j.febslet.2005.08.019.

23. Deeb, R.S.; Nuriel, T.; Cheung, C.; Summers, B.; Lamon, B.D.; Gross, S.S.; Hajjar, D.P. Characterization of a cellular denitrase activity that reverses nitration of cyclooxygenase. $\mathrm{Am}$ J Physiol Heart Circ Physiol 2013, 305, H687-698, doi:10.1152/ajpheart.00876.2012.

24. Kang, J.W.; Lee, N.Y.; Cho, K.C.; Lee, M.Y.; Choi, D.Y.; Park, S.H.; Kim, K.P. Analysis of nitrated proteins in Saccharomyces cerevisiae involved in mating signal transduction. Proteomics 2015, 15, 580-590, doi:10.1002/pmic.201400172.

25. Lim, J.M.; Kim, G.; Levine, R.L. Methionine in Proteins: It's Not Just for Protein Initiation Anymore. Neurochem Res 2019, 44, 247-257, doi:10.1007/s11064-017-2460-0.

26. Beedle, A.E.; Lynham, S.; Garcia-Manyes, S. Protein S-sulfenylation is a fleeting molecular switch that regulates non-enzymatic oxidative folding. Nat Commun 2016, 7, 12490, doi:10.1038/ncomms12490.

27. Chen, C.A.; Wang, T.Y.; Varadharaj, S.; Reyes, L.A.; Hemann, C.; Talukder, M.A.; Chen, Y.R.; Druhan, L.J.; Zweier, J.L. S-glutathionylation uncouples eNOS and regulates its cellular and vascular function. Nature 2010, 468, 1115-1118, doi:10.1038/nature09599.

28. Koeck, T.; Fu, X.; Hazen, S.L.; Crabb, J.W.; Stuehr, D.J.; Aulak, K.S. Rapid and selective oxygenregulated protein tyrosine denitration and nitration in mitochondria. J Biol Chem 2004, 279, 27257-27262, doi:10.1074/jbc.M401586200.

29. Forstermann, U.; Sessa, W.C. Nitric oxide synthases: regulation and function. Eur Heart J 2012, 33, 829-837, 837a-837d, doi:10.1093/eurheartj/ehr304.

30. Aquilano, K.; Baldelli, S.; Ciriolo, M.R. Nuclear recruitment of neuronal nitric-oxide synthase by $\alpha$-syntrophin is crucial for the induction of mitochondrial biogenesis. J Biol Chem 2014, 289, 365-378, doi:10.1074/jbc.M113.506733.

31. Balke, J.E.; Zhang, L.; Percival, J.M. Neuronal nitric oxide synthase (nNOS) splice variant function: Insights into nitric oxide signaling from skeletal muscle. Nitric Oxide 2019, 82, 35-47, doi:10.1016/j.niox.2018.11.004. 
32. Kobayashi, J.; Uchida, H.; Kofuji, A.; Ito, J.; Shimizu, M.; Kim, H.; Sekiguchi, Y.; Kushibe, S. Molecular regulation of skeletal muscle mass and the contribution of nitric oxide: A review. FASEB bioAdvances 2019, 1, 364-374, doi:10.1096/fba.2018-00080.

33. Lechado, I.T.A.; Vitadello, M.; Traini, L.; Namuduri, A.V.; Gastaldello, S.; Gorza, L. Sarcolemmal loss of active nNOS (Nos1) is an oxidative stress-dependent, early event driving disuse atrophy. J Pathol 2018, 246, 433-446, doi:10.1002/path.5149.

34. Salanova, M.; Schiffl, G.; Gutsmann, M.; Felsenberg, D.; Furlan, S.; Volpe, P.; Clarke, A.; Blottner, D. Nitrosative stress in human skeletal muscle attenuated by exercise countermeasure after chronic disuse. Redox Biology 2013, 1, 514-526, doi:10.1016/j.redox.2013.10.006.

35. Maron, B.A.; Michel, T. Subcellular localization of oxidants and redox modulation of endothelial nitric oxide synthase. Circ. J. 2012, 76, 2497-2512, doi:10.1253/circj.cj-12-1207.

36. Zweier, J.L.; Chen, C.A.; Druhan, L.J. S-glutathionylation reshapes our understanding of endothelial nitric oxide synthase uncoupling and nitric oxide/reactive oxygen speciesmediated signaling. Antioxid Redox Signal 2011, 14, 1769-1775, doi:10.1089/ars.2011.3904.

37. Ravi, K.; Brennan, L.A.; Levic, S.; Ross, P.A.; Black, S.M. S-nitrosylation of endothelial nitric oxide synthase is associated with monomerization and decreased enzyme activity. Proc Natl Acad Sci U S A 2004, 101, 2619-2624, doi:10.1073/pnas.0300464101.

38. Drab, M.; Verkade, P.; Elger, M.; Kasper, M.; Lohn, M.; Lauterbach, B.; Menne, J.; Lindschau, C.; Mende, F.; Luft, F.C.; et al. Loss of caveolae, vascular dysfunction, and pulmonary defects in caveolin-1 gene-disrupted mice. Science 2001, 293, 2449-2452, doi:10.1126/science.1062688.

39. Chen, Z.; S, D.S.O.; Zimnicka, A.M.; Jiang, Y.; Sharma, T.; Chen, S.; Lazarov, O.; Bonini, M.G.; Haus, J.M.; Minshall, R.D. Reciprocal regulation of eNOS and caveolin-1 functions in endothelial cells. Mol Biol Cell 2018, 29, 1190-1202, doi:10.1091/mbc.E17-01-0049.

40. Porter, J.J.; Jang, H.S.; Haque, M.M.; Stuehr, D.J.; Mehl, R.A. Tyrosine Nitration on Calmodulin Enhances calcium-dependent association and activation of Nitric Oxide Synthase. J Biol Chem 2019.

41. Spiller, F.; Oliveira Formiga, R.; Fernandes da Silva Coimbra, J.; Alves-Filho, J.C.; Cunha, T.M.; Cunha, F.Q. Targeting nitric oxide as a key modulator of sepsis, arthritis and pain. Nitric Oxide 2019, 89, 32-40, doi:10.1016/j.niox.2019.04.011.

42. Karbach, S.; Wenzel, P.; Waisman, A.; Munzel, T.; Daiber, A. eNOS uncoupling in cardiovascular diseases--the role of oxidative stress and inflammation. Curr Pharm Des 2014, 20, 3579-3594, doi:10.2174/13816128113196660748.

43. Meza, C.A.; La Favor, J.D.; Kim, D.H.; Hickner, R.C. Endothelial Dysfunction: Is There a Hyperglycemia-Induced Imbalance of NOX and NOS? Int J Mol Sci 2019, 20, doi:10.3390/ijms20153775.

44. Navia-Pelaez, J.M.; Campos-Mota, G.P.; Araujo de Souza, J.C.; Aguilar, E.C.; Stergiopulos, N.; Alvarez-Leite, J.I.; Capettini, L.S.A. nNOS uncoupling by oxidized LDL: Implications in atherosclerosis. Free Radic Biol Med 2017, 113, 335-346, doi:10.1016/j.freeradbiomed.2017.09.018.

45. Sharma, N.M.; Patel, K.P. Post-translational regulation of neuronal nitric oxide synthase: implications for sympathoexcitatory states. Expert Opin. Ther. Targets 2017, 21, 11-22, doi:10.1080/14728222.2017.1265505. 
46. Ridnour, L.A.; Thomas, D.D.; Switzer, C.; Flores-Santana, W.; Isenberg, J.S.; Ambs, S.; Roberts, D.D.; Wink, D.A. Molecular mechanisms for discrete nitric oxide levels in cancer. Nitric Oxide 2008, 19, 73-76, doi:10.1016/j.niox.2008.04.006.

47. Thomas, D.D.; Heinecke, J.L.; Ridnour, L.A.; Cheng, R.Y.; Kesarwala, A.H.; Switzer, C.H.; McVicar, D.W.; Roberts, D.D.; Glynn, S.; Fukuto, J.M.; et al. Signaling and stress: The redox landscape in NOS2 biology. Free Radic Biol Med 2015, 87, 204-225, doi:10.1016/j.freeradbiomed.2015.06.002.

48. Csibi, A.; Communi, D.; Muller, N.; Bottari, S.P. Angiotensin II inhibits insulin-stimulated GLUT4 translocation and Akt activation through tyrosine nitration-dependent mechanisms. PLoS One 2010, 5, e10070, doi:10.1371/journal.pone.0010070.

49. Horvath, T.L.; Andrews, Z.B.; Diano, S. Fuel utilization by hypothalamic neurons: roles for ROS. Trends Endocrinol Metab 2009, 20, 78-87, doi:10.1016/j.tem.2008.10.003.

50. Niemann, B.; Rohrbach, S.; Miller, M.R.; Newby, D.E.; Fuster, V.; Kovacic, J.C. Oxidative Stress and Cardiovascular Risk: Obesity, Diabetes, Smoking, and Pollution: Part 3 of a 3-Part Series. J Am Coll Cardiol 2017, 70, 230-251, doi:10.1016/j.jacc.2017.05.043.

51. Gyuraszova, M.; Gurecka, R.; Babickova, J.; Tothova, L. Oxidative Stress in the Pathophysiology of Kidney Disease: Implications for Noninvasive Monitoring and Identification of Biomarkers. Oxid Med Cell Longev 2020, 2020, 5478708, doi:10.1155/2020/5478708.

52. Poulet, B.; Beier, F. Targeting oxidative stress to reduce osteoarthritis. Arthritis Res Ther 2016, 18, 32, doi:10.1186/s13075-015-0908-7.

53. Zinczuk, J.; Maciejczyk, M.; Zareba, K.; Pryczynicz, A.; Dymicka-Piekarska, V.; Kaminska, J.; Koper-Lenkiewicz, O.; Matowicka-Karna, J.; Kedra, B.; Zalewska, A.; et al. Pro-Oxidant Enzymes, Redox Balance and Oxidative Damage to Proteins, Lipids and DNA in Colorectal Cancer Tissue. Is Oxidative Stress Dependent on Tumour Budding and Inflammatory Infiltration? Cancers (Basel) 2020, 12, doi:10.3390/cancers12061636.

54. Bondia-Pons, I.; Ryan, L.; Martinez, J.A. Oxidative stress and inflammation interactions in human obesity. J Physiol Biochem 2012, 68, 701-711, doi:10.1007/s13105-012-0154-2.

55. Goossens, G.H. The Metabolic Phenotype in Obesity: Fat Mass, Body Fat Distribution, and Adipose Tissue Function. Obes Facts 2017, 10, 207-215, doi:10.1159/000471488.

56. Larsen, T.S.; Jansen, K.M. Impact of Obesity-Related Inflammation on Cardiac Metabolism and Function. J Lipid Atheroscler 2021, 10, 8-23, doi:10.12997/jla.2021.10.1.8.

57. Ortega, F.B.; Lee, D.C.; Katzmarzyk, P.T.; Ruiz, J.R.; Sui, X.; Church, T.S.; Blair, S.N. The intriguing metabolically healthy but obese phenotype: cardiovascular prognosis and role of fitness. Eur Heart J 2013, 34, 389-397, doi:10.1093/eurheartj/ehs174.

58. Samouda, H.; Ruiz-Castell, M.; Karimi, M.; Bocquet, V.; Kuemmerle, A.; Chioti, A.; Dadoun, F.; Stranges, S. Metabolically healthy and unhealthy weight statuses, health issues and related costs: Findings from the 2013-2015 European Health Examination Survey in Luxembourg. Diabetes Metab 2019, 45, 140-151, doi:10.1016/j.diabet.2017.11.007.

59. Lejawa, M.; Osadnik, K.; Osadnik, T.; Pawlas, N. Association of Metabolically Healthy and Unhealthy Obesity Phenotypes with Oxidative Stress Parameters and Telomere Length in Healthy Young Adult Men. Analysis of the MAGNETIC Study. Antioxidants (Basel) 2021, 10, doi:10.3390/antiox10010093.

60. Stefan, N.; Haring, H.U.; Hu, F.B.; Schulze, M.B. Metabolically healthy obesity: epidemiology, mechanisms, and clinical implications. Lancet Diabetes Endocrinol 2013, 1, 152-162, doi:10.1016/S2213-8587(13)70062-7. 
61. Vecchie, A.; Dallegri, F.; Carbone, F.; Bonaventura, A.; Liberale, L.; Portincasa, P.; Fruhbeck, G.; Montecucco, F. Obesity phenotypes and their paradoxical association with cardiovascular diseases. Eur J Intern Med 2018, 48, 6-17, doi:10.1016/j.ejim.2017.10.020.

62. Fung, M.D.; Canning, K.L.; Mirdamadi, P.; Ardern, C.I.; Kuk, J.L. Lifestyle and weight predictors of a healthy overweight profile over a 20-year follow-up. Obesity (Silver Spring) 2015, 23, 13201325, doi:10.1002/oby.21087.

63. Alam, I.; Ng, T.P.; Larbi, A. Does inflammation determine whether obesity is metabolically healthy or unhealthy? The aging perspective. Mediators Inflamm 2012, 2012, 456456, doi:10.1155/2012/456456.

64. Shoelson, S.E.; Lee, J.; Goldfine, A.B. Inflammation and insulin resistance. J Clin Invest 2006, 116, 1793-1801, doi:10.1172/JCI29069.

65. Hotamisligil, G.S.; Shargill, N.S.; Spiegelman, B.M. Adipose expression of tumor necrosis factoralpha: direct role in obesity-linked insulin resistance. Science 1993, 259, 87-91, doi:10.1126/science.7678183.

66. Kim, C.S.; Park, H.S.; Kawada, T.; Kim, J.H.; Lim, D.; Hubbard, N.E.; Kwon, B.S.; Erickson, K.L.; $\mathrm{Yu}, \mathrm{R}$. Circulating levels of MCP-1 and IL-8 are elevated in human obese subjects and associated with obesity-related parameters. Int J Obes (Lond) 2006, 30, 1347-1355, doi:10.1038/sj.ijo.0803259.

67. Tilg, H.; Moschen, A.R. Adipocytokines: mediators linking adipose tissue, inflammation and immunity. Nat Rev Immunol 2006, 6, 772-783, doi:10.1038/nri1937.

68. Christou, K.A.; Christou, G.A.; Karamoutsios, A.; Vartholomatos, G.; Gartzonika, K.; Tsatsoulis, A.; Tigas, $\mathrm{S}$. The regulation of serum resistin levels in metabolically healthy and unhealthy obese individuals. Hormones (Athens) 2020, 19, 523-529, doi:10.1007/s42000-020-00201-1.

69. Lee, B.C.; Lee, J. Cellular and molecular players in adipose tissue inflammation in the development of obesity-induced insulin resistance. Biochim Biophys Acta 2014, 1842, 446-462, doi:10.1016/j.bbadis.2013.05.017.

70. Moghbeli, M.; Khedmatgozar, H.; Yadegari, M.; Avan, A.; Ferns, G.A.; Ghayour Mobarhan, M. Cytokines and the immune response in obesity-related disorders. Adv Clin Chem 2021, 101, 135-168, doi:10.1016/bs.acc.2020.06.004.

71. Pirola, L.; Ferraz, J.C. Role of pro- and anti-inflammatory phenomena in the physiopathology of type 2 diabetes and obesity. World J Biol Chem 2017, 8, 120-128, doi:10.4331/wjbc.v8.i2.120.

72. Ryder, E.; Diez-Ewald, M.; Mosquera, J.; Fernandez, E.; Pedreanez, A.; Vargas, R.; Pena, C.; Fernandez, N. Association of obesity with leukocyte count in obese individuals without metabolic syndrome. Diabetes Metab Syndr 2014, 8, 197-204, doi:10.1016/j.dsx.2014.09.002.

73. Lorenzo, C.; Hanley, A.J.; Haffner, S.M. Differential white cell count and incident type 2 diabetes: the Insulin Resistance Atherosclerosis Study. Diabetologia 2014, 57, 83-92, doi:10.1007/s00125-013-3080-0.

74. Mirhafez, S.R.; Zarifian, A.; Ebrahimi, M.; Ali, R.F.; Avan, A.; Tajfard, M.; Mohebati, M.; Eslami, S.; Rahsepar, A.A.; Rahimi, H.R.; et al. Relationship between serum cytokine and growth factor concentrations and coronary artery disease. Clin Biochem 2015, 48, 575-580, doi:10.1016/j.clinbiochem.2015.02.002.

75. Landin, K.; Krotkiewski, M.; Smith, U. Importance of obesity for the metabolic abnormalities associated with an abdominal fat distribution. Metabolism 1989, 38, 572-576, doi:10.1016/0026-0495(89)90219-9. 
76. Longo, M.; Zatterale, F.; Naderi, J.; Parrillo, L.; Formisano, P.; Raciti, G.A.; Beguinot, F.; Miele, C. Adipose Tissue Dysfunction as Determinant of Obesity-Associated Metabolic Complications. Int J Mol Sci 2019, 20, doi:10.3390/ijms20092358.

77. Porro, S.; Genchi, V.A.; Cignarelli, A.; Natalicchio, A.; Laviola, L.; Giorgino, F.; Perrini, S. Dysmetabolic adipose tissue in obesity: morphological and functional characteristics of adipose stem cells and mature adipocytes in healthy and unhealthy obese subjects. I Endocrinol Invest 2021, 44, 921-941, doi:10.1007/s40618-020-01446-8.

78. Morelli, M.; Gaggini, M.; Daniele, G.; Marraccini, P.; Sicari, R.; Gastaldelli, A. Ectopic fat: the true culprit linking obesity and cardiovascular disease? Thromb Haemost 2013, 110, 651-660, doi:10.1160/TH13-04-0285.

79. de Heredia, F.P.; Gomez-Martinez, S.; Marcos, A. Obesity, inflammation and the immune system. Proc Nutr Soc 2012, 71, 332-338, doi:10.1017/\$0029665112000092.

80. Gozal, D.; Gileles-Hillel, A.; Cortese, R.; Li, Y.; Almendros, I.; Qiao, Z.; Khalyfa, A.A.; Andrade, J.; Khalyfa, A. Visceral White Adipose Tissue after Chronic Intermittent and Sustained Hypoxia in Mice. Am J Respir Cell Mol Biol 2017, 56, 477-487, doi:10.1165/rcmb.2016-02430C.

81. Gileles-Hillel, A.; Almendros, I.; Khalyfa, A.; Nigdelioglu, R.; Qiao, Z.; Hamanaka, R.B.; Mutlu, G.M.; Akbarpour, M.; Gozal, D. Prolonged Exposures to Intermittent Hypoxia Promote Visceral White Adipose Tissue Inflammation in a Murine Model of Severe Sleep Apnea: Effect of Normoxic Recovery. Sleep 2017, 40, doi:10.1093/sleep/zsw074.

82. Cifarelli, V.; Beeman, S.C.; Smith, G.I.; Yoshino, J.; Morozov, D.; Beals, J.W.; Kayser, B.D.; Watrous, J.D.; Jain, M.; Patterson, B.W.; et al. Decreased adipose tissue oxygenation associates with insulin resistance in individuals with obesity. J Clin Invest 2020, 130, 6688-6699, doi:10.1172/JCl141828.

83. Cancello, R.; Tordjman, J.; Poitou, C.; Guilhem, G.; Bouillot, J.L.; Hugol, D.; Coussieu, C.; Basdevant, A.; Bar Hen, A.; Bedossa, P.; et al. Increased infiltration of macrophages in omental adipose tissue is associated with marked hepatic lesions in morbid human obesity. Diabetes 2006, 55, 1554-1561, doi:10.2337/db06-0133.

84. Malavazos, A.E.; Corsi Romanelli, M.M.; Bandera, F.; lacobellis, G. Targeting the Adipose Tissue in COVID-19. Obesity (Silver Spring) 2020, https://doi.org/10.1002/oby.22844, doi:10.1002/oby.22844.

85. Surmi, B.K.; Hasty, A.H. Macrophage infiltration into adipose tissue: initiation, propagation and remodeling. Future Lipidol 2008, 3, 545-556, doi:10.2217/17460875.3.5.545.

86. Maurizi, G.; Della Guardia, L.; Maurizi, A.; Poloni, A. Adipocytes properties and crosstalk with immune system in obesity-related inflammation. J Cell Physiol 2018, 233, 88-97, doi:10.1002/jcp.25855.

87. Myers, M.G., Jr.; Leibel, R.L.; Seeley, R.J.; Schwartz, M.W. Obesity and leptin resistance: distinguishing cause from effect. Trends Endocrinol Metab 2010, 21, 643-651, doi:10.1016/j.tem.2010.08.002.

88. Sanchez-Margalet, V.; Martin-Romero, C.; Santos-Alvarez, J.; Goberna, R.; Najib, S.; GonzalezYanes, C. Role of leptin as an immunomodulator of blood mononuclear cells: mechanisms of action. Clin Exp Immunol 2003, 133, 11-19, doi:10.1046/j.1365-2249.2003.02190.x.

89. Ibrahim, H.S.; Froemming, G.R.; Omar, E.; Singh, H.J. ACE2 activation by xanthenone prevents leptin-induced increases in blood pressure and proteinuria during pregnancy in SpragueDawley rats. Reprod Toxicol 2014, 49, 155-161, doi:10.1016/j.reprotox.2014.08.006. 
90. Hernandez-Morante, J.J.; Milagro, F.; Gabaldon, J.A.; Martinez, J.A.; Zamora, S.; Garaulet, M. Effect of DHEA-sulfate on adiponectin gene expression in adipose tissue from different fat depots in morbidly obese humans. Eur J Endocrinol 2006, 155, 593-600, doi:10.1530/eje.1.02256.

91. Fain, J.N. Release of inflammatory mediators by human adipose tissue is enhanced in obesity and primarily by the nonfat cells: a review. Mediators Inflamm 2010, 2010, 513948, doi:10.1155/2010/513948.

92. Yang, R.Z.; Lee, M.J.; Hu, H.; Pollin, T.I.; Ryan, A.S.; Nicklas, B.J.; Snitker, S.; Horenstein, R.B.; Hull, K.; Goldberg, N.H.; et al. Acute-phase serum amyloid A: an inflammatory adipokine and potential link between obesity and its metabolic complications. PLoS Med 2006, 3, e287, doi:10.1371/journal.pmed.0030287.

93. Kawai, T.; Autieri, M.V.; Scalia, R. Adipose tissue inflammation and metabolic dysfunction in obesity. Am J Physiol Cell Physiol 2021, 320, C375-C391, doi:10.1152/ajpcell.00379.2020.

94. Scalia, R. The microcirculation in adipose tissue inflammation. Rev Endocr Metab Disord 2013, 14, 69-76, doi:10.1007/s11154-013-9236-x.

95. Harman-Boehm, I.; Bluher, M.; Redel, H.; Sion-Vardy, N.; Ovadia, S.; Avinoach, E.; Shai, I.; Kloting, N.; Stumvoll, M.; Bashan, N.; et al. Macrophage infiltration into omental versus subcutaneous fat across different populations: effect of regional adiposity and the comorbidities of obesity. J Clin Endocrinol Metab 2007, 92, 2240-2247, doi:10.1210/jc.20061811.

96. Hardy, O.T.; Perugini, R.A.; Nicoloro, S.M.; Gallagher-Dorval, K.; Puri, V.; Straubhaar, J.; Czech, M.P. Body mass index-independent inflammation in omental adipose tissue associated with insulin resistance in morbid obesity. Surg Obes Relat Dis 2011, 7, 60-67, doi:10.1016/j.soard.2010.05.013.

97. Ortega Martinez de Victoria, E.; Xu, X.; Koska, J.; Francisco, A.M.; Scalise, M.; Ferrante, A.W., Jr.; Krakoff, J. Macrophage content in subcutaneous adipose tissue: associations with adiposity, age, inflammatory markers, and whole-body insulin action in healthy Pima Indians. Diabetes 2009, 58, 385-393, doi:10.2337/db08-0536.

98. Bai, Y.; Sun, Q. Macrophage recruitment in obese adipose tissue. Obes Rev 2015, 16, 127-136, doi:10.1111/obr.12242.

99. Taylor, E.B. The complex role of adipokines in obesity, inflammation, and autoimmunity. Clin Sci (Lond) 2021, 135, 731-752, doi:10.1042/CS20200895.

100. Kammoun, H.L.; Kraakman, M.J.; Febbraio, M.A. Adipose tissue inflammation in glucose metabolism. Rev Endocr Metab Disord 2014, 15, 31-44, doi:10.1007/s11154-013-9274-4.

101. Navegantes, K.C.; de Souza Gomes, R.; Pereira, P.A.T.; Czaikoski, P.G.; Azevedo, C.H.M.; Monteiro, M.C. Immune modulation of some autoimmune diseases: the critical role of macrophages and neutrophils in the innate and adaptive immunity. J Trans/ Med 2017, 15, 36, doi:10.1186/s12967-017-1141-8.

102. Heinonen, S.; Jokinen, R.; Rissanen, A.; Pietilainen, K.H. White adipose tissue mitochondrial metabolism in health and in obesity. Obes Rev 2020, 21, e12958, doi:10.1111/obr.12958.

103. Valenti, D.; Vacca, R.A.; Moro, L.; Atlante, A. Mitochondria Can Cross Cell Boundaries: An Overview of the Biological Relevance, Pathophysiological Implications and Therapeutic Perspectives of Intercellular Mitochondrial Transfer. Int J Mol Sci 2021, 22, doi:10.3390/ijms22158312. 
104. Brestoff, J.R.; Wilen, C.B.; Moley, J.R.; Li, Y.; Zou, W.; Malvin, N.P.; Rowen, M.N.; Saunders, B.T.; Ma, H.; Mack, M.R.; et al. Intercellular Mitochondria Transfer to Macrophages Regulates White Adipose Tissue Homeostasis and Is Impaired in Obesity. Cell Metab 2021, 33, 270-282 e278, doi:10.1016/j.cmet.2020.11.008.

105. Clement, E.; Lazar, I.; Attane, C.; Carrie, L.; Dauvillier, S.; Ducoux-Petit, M.; Esteve, D.; Menneteau, T.; Moutahir, M.; Le Gonidec, S.; et al. Adipocyte extracellular vesicles carry enzymes and fatty acids that stimulate mitochondrial metabolism and remodeling in tumor cells. EMBO J 2020, 39, e102525, doi:10.15252/embj.2019102525.

106. Lecoutre, S.; Clement, K.; Dugail, I. Obesity-Related Adipose Tissue Remodeling in the Light of Extracellular Mitochondria Transfer. Int J Mol Sci 2022, 23, doi:10.3390/ijms23020632.

107. Gilbert, M. Role of skeletal muscle lipids in the pathogenesis of insulin resistance of obesity and type 2 diabetes. J Diabetes Investig 2021, 12, 1934-1941, doi:10.1111/jdi.13614.

108. Chanseaume, E.; Morio, B. Potential mechanisms of muscle mitochondrial dysfunction in aging and obesity and cellular consequences. Int $J$ Mol Sci 2009, 10, 306-324, doi:10.3390/ijms10010306.

109. Pileggi, C.A.; Parmar, G.; Harper, M.E. The lifecycle of skeletal muscle mitochondria in obesity. Obes Rev 2021, 22, e13164, doi:10.1111/obr.13164.

110. Wu, H.; Ballantyne, C.M. Skeletal muscle inflammation and insulin resistance in obesity. $J$ Clin Invest 2017, 127, 43-54, doi:10.1172/JCl88880.

111. Tavernarakis, N. Inflammation brakes mitochondrial metabolism in obesity. Nat Immunol 2020, 21, 1143-1145, doi:10.1038/s41590-020-0780-8. 


\section{Figure Legends}

Fig. 1: Schematic representation of the major mechanisms and reactions involved in redox signaling with emphasis on the generation and degradation of reactive oxygen species (ROS)

Fig. 2: Schematic representation of the major mechanisms and reactions involved in redox signaling with emphasis on the generation and effects of reactive nitrogen species (RNS)

Fig. 3: Impact of obesity on the metabolism and immune status of visceral adipose tissue and its effects on reactive species generation. Consequences on skeletal muscle and mitochondrial dysfunction are highlighted. 